\title{
Davis school program supports life-long healthy eating habits in children
}

\author{
Heather Graham \\ Gail Feenstra \\ Ann M. Evans \\ Sheri Zidenberg-Cherr
}

The school environment can positively affect students in areas beyond traditional academic achievement. An innovative program in Davis, the Farm to School Connection, sought to promote the development of life-long healthy eating habits in children and to create a school environment that made connections among the school garden, cafeteria and classroom, and linked them to local agriculture. This comprehensive program included farmers' market salad bars, classroom education, farm tours and waste management. We evaluated the effectiveness of the program via interviews and surveys of program leaders, teachers and school staff. Participation in the school lunch program increased with the addition of the salad bars, and numerous partnerships developed among those involved. Components of the Farm to School Connection provide evidence to support comprehensive school nutrition programs and the positive impact they can have on the school environment.

\section{$\Lambda T$ a time when childhood over- $A 1$ weight and obesity are at} record highs, educators can utilize the school environment to link schools with families and communities, in order to promote healthy lifestyles and prevent obesity and associated diseases. The percentage of children in the United States who are overweight increased from $7 \%$ in 1980 to $15 \%$ in 2000, and the percentage of overweight adolescents increased from 5\% in 1980 to $15 \%$ in 2000 (Ogden et al. 2002). In California,
$34 \%$ of children and $21 \%$ of adolescents are overweight or at risk for overweight (Foerster et al. 2002). Obesity or overweight status places individuals at risk for several chronic health problems (CDC 2003; Epstein et al. 1985; Rosenbaum et al. 1999; Whitaker et al. 1997). Obesity not only adversely affects health, it can also negatively affect a child emotionally and socially. Obese children and adolescents often have a lower health-related quality of life as compared with nonobese, healthy children and adolescents, affecting their ability to participate in normal social behaviors, such as sports and playground activities (Schwimmer et al. 2003).

One prudent step toward improving child health is for schools to move beyond their traditional academic role to take an active role in promoting healthier lifestyles, families and communities.
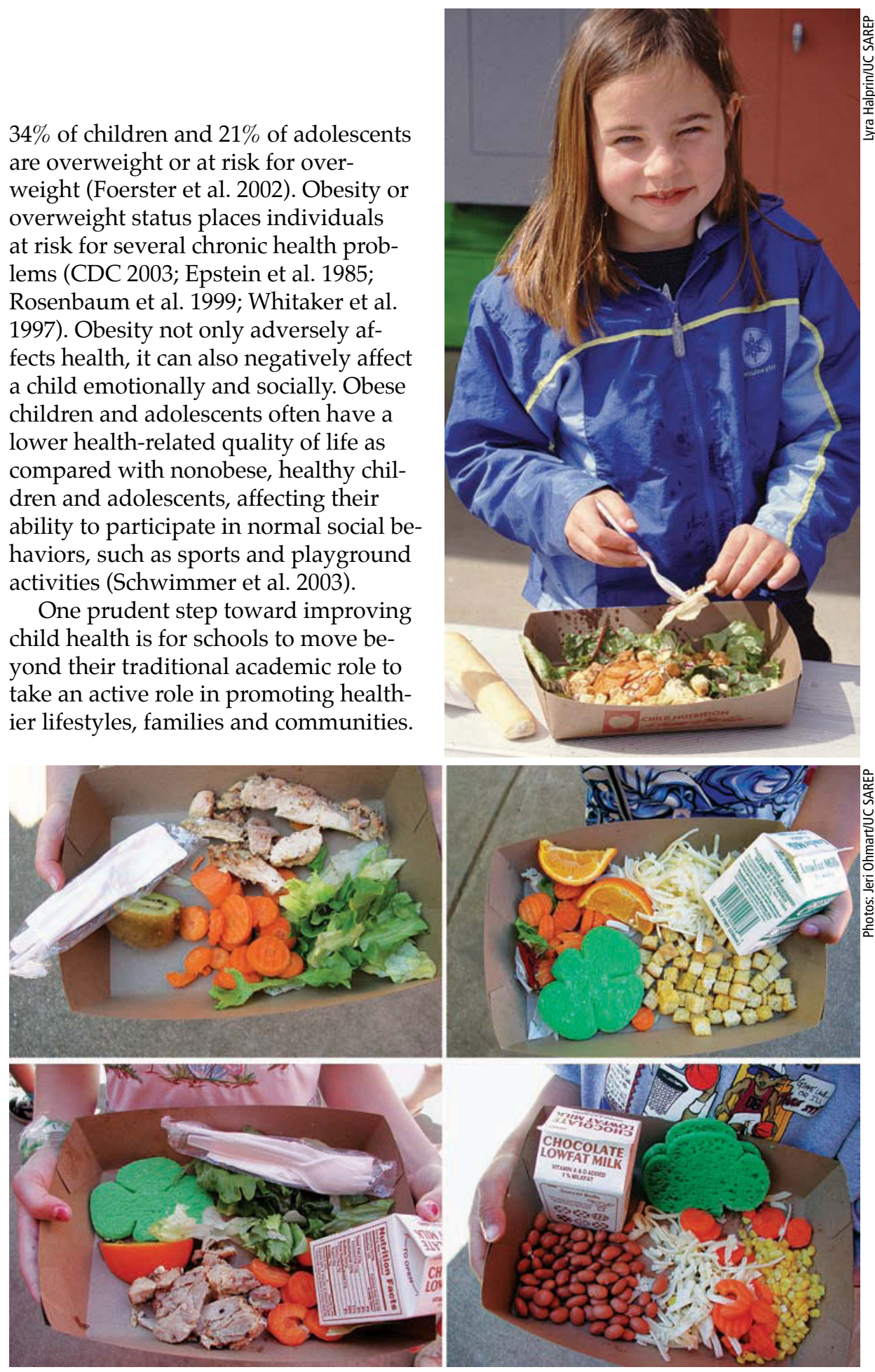

In Davis elementary schools, children can choose what they want for lunch from salad bars stocked with healthy fare, including fruits and vegetables supplied by regional growers. 
The U.S. Centers for Disease Control (CDC) encourages creating a school environment that supports regular physical activity and healthy eating habits (CDC 1996, 2003). This includes ensuring quality meal service for students, monitoring the sale of competitive foods and providing an environment that promotes good health.

\section{Bringing agriculture into schools}

In the past, Americans were more aware of the important role farming played in their lives. Many worked on farms or lived in farming communities. Today, however, most people live in urban areas. Although California still has bountiful agriculture, fewer and fewer of its residents are aware of the impact farming has on their lives. Children, especially, have lost touch with how and where food is grown. They lack an understanding of the ecosystems, the land, the people and even the plants that produce their food (CDE 2002).

Many school districts throughout California have shown an interest in "stepping out of the box" of traditional teaching methods to incorporate agriculture into the school environment (Graham et al. in press). The incorporation of agriculture into the school curriculum provides an excellent avenue in which to discuss food - where it comes from, its health benefits, how to choose healthy foods and factors contributing to human health, as well as concepts important to planetary health, such as composting and recycling.

We describe a comprehensive model program initiated by the Davis Joint Unified School District (DJUSD), which incorporates agriculture into the school environment. This program embraces a "seed to table" philosophy, in which every part of the school environment, from gardens to the cafeteria to the classroom, are part of a consistent and repetitive message to students - that healthy eating habits can be learned through participation in the full cycle of life from seed to table and back again. The environment is used as the focal point for learning, as environmentally based learning has been shown to be an effective route for enhanced learning, resulting in higher grades and improved standardized test scores (Lieberman and Hoody 1998).

In 1999, the Davis Farm to School Connection was formed with the assistance of various community and government organizations including the Davis Farmers' Market, DJUSD, UC, Davis Children's Garden, Yolo County Office of Education, UC Sustainable Agriculture Research and Education Program (UC SAREP), California Department of Education (CDE), California Integrated Waste Management Board (CIWMB) and Community Alliance with Family Farmers (CAFF). Formal evaluation of the program took place from 2001 through 2003.

The program initiated farmers' market salad bars, first in three and later in all DJUSD elementary schools; this provided an opportunity for local farmers to expand their markets by selling produce to the school district. The program offered farm tours to second-grade classes, used established instructional gardens for hands-on learning experiences included recycling and composting, and integrated classroom curricula with garden activities and farm tours.
In addition, the garden "laboratory" was integrated with nutrition education, because garden-enhanced nutrition education is an effective avenue to improve children's knowledge of nutrition and vegetable preferences (Morris and Zidenberg-Cherr 2002).

\section{Farmers' market salad bars}

In 2001, the first three farmers' market salad bars, termed "Crunch Lunch," were established in three elementary schools, featuring fresh fruits and vegetables (organic when possible) purchased directly from regional growers. The salad bars were designed for students to serve themselves from a variety of fresh vegetables, fruits and protein sources (beans, tuna, turkey and cheese). Students were usually allowed to return to the salad bar, which was the same price as the standard hot lunch. During the first 2 years, Crunch Lunch was offered as a separate option to the hot lunch meal 5 days per week. In the third year, the model was changed to an integrated salad bar/hot lunch option in which the salad bar was offered with the hot lunch every day.

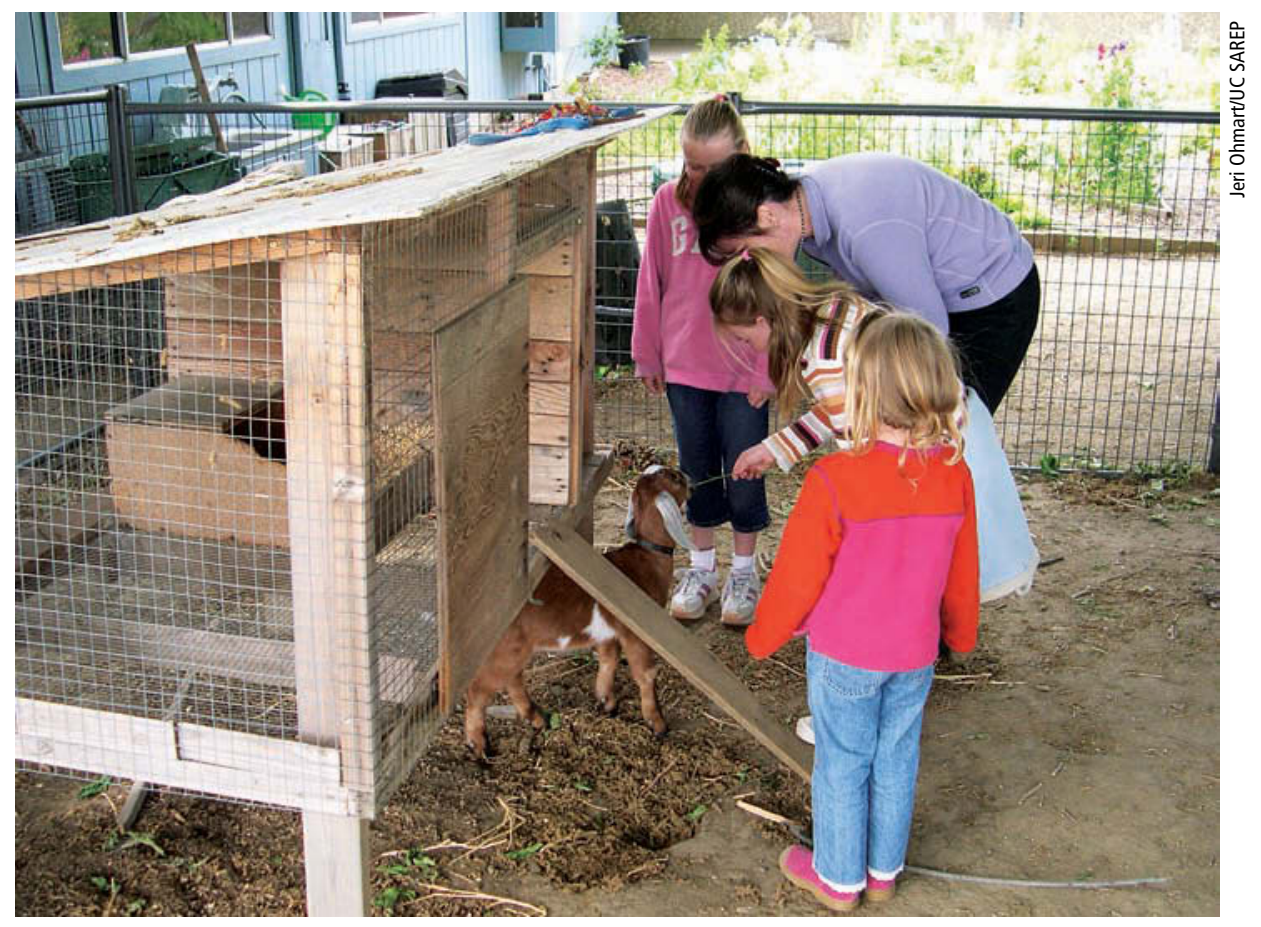

At the Birch Lane Elementary School in Davis, students keep animals as part of the Farm to School Connection. Other components of the program include farmers' market salad bars, farm tours and garden-based education. 


\section{The Farm to School Connection serves as an example of how incorporating agricultural concepts within school curricula can facilitate teaching to core curriculum standards for}

math, science, language arts and social science.

Overall, Crunch Lunch has been popular with the students, and participation in the school lunch program has increased. In a recent review, participation was measured based on the number of enrolled students who purchased lunch from the salad bar. Participation in the three salad bar schools was greater $(37.4 \%)$ than in non-salad bar schools (27\%) during the 2001-2002 school year (September to June). Participation moderated somewhat during the 2002-2003 school year, to about 33\% in salad bar schools compared to $26 \%$ in the non-salad bar schools (Feenstra and Ohmart 2003).

The amounts of fruits and vegetables children took from the salad bar declined somewhat in the third year when the model changed to an integrated salad bar/hot lunch. Program leaders suspect that this may have been partly due to a diminished focus on the salad bar as the centerpiece of the meal and the fact that there is less room on the plate for the salad when there is a hot entrée. The novelty of the salad bar may also have worn off since it was available every day. As of this writing, the foodservice staff is considering changing the model again to "salad bar only" on the days the salad bar is offered. This model has been extremely popular in other school districts such as Winters and Ventura (Feenstra and Ohmart 2003).

\section{Staff perceptions of salad bars}

During the 2001-2002 school year, we interviewed staff for their perceptions of the salad bar as well as to assess partnership development among DJUSD staff involved in the program. The interviews included questions on the effect of the salad bar on the school environment; whether the program has affected work flow; how the salad bar affects student diets; how the salad bar is working in terms of staff and logistics of preparation, delivery and service; positive and negative effects since the program started; training received for initiation of the salad bar; and any present or future challenges. Food-service staff were also asked one additional question specific to preparation and service of the salad bar.

Staff members at the three pilot school sites were asked to voluntarily participate in the group interviews. They included staff directly involved with the gardens at one or more sites $(\mathrm{n}=8)$, teachers $(\mathrm{n}=7)$ and foodservice staff directly involved with preparation and service of the salad bar $(n=3)$. Three separate groups were interviewed, and the different types of staff were interviewed separately (garden, teachers and food-service). A moderator facilitated the semistructured discussions and an assistant recorded responses. All interviews were audio-taped and written notes were taken. The transcribed interviews were analyzed to identify common themes within each group and as an entire group. All procedures were reviewed and approved by the UC Davis Committee on the Use of Human Subjects, as well as the DJUSD. Recurring themes were identified, with special attention paid to the participants' responses to the seven or eight questions.

Student diets. Participants noted that they saw an overall positive effect on the students' diets and that the children were excited about having a salad bar as a lunch option. One staff member stated "students will switch from hot lunch if they see items they like in the salad bar." Others noticed that children often discarded their vegetables when eating a hot lunch, but did this less often with the salad bar.

\section{Choices and portions. Teachers} stated that they liked the idea of the children having the independence to make their own choices and learn about portion sizes. There was concern about children putting enough food on their plates. Some teachers believed that knowledge of portion sizes among students was lacking and that guidance in making food choices was essential. Two teachers stated that some students placed too much on their plates, leading to unnecessary food waste. Food- service staff noted that additional training would assist them in gaining knowledge of serving sizes in order to better assist the children in making adequate choices. One food-service staff member stated that information was needed on "what a serving of strawberries looks like." Another noticed effect was decreased plate waste.

Cafeteria environment. Participants stated that the lunch period was "calmer" with the addition of the salad bar. It was also mentioned that lunch became more social among students, who discussed the foods on the salad bar. Overall, those interviewed noted that the salad bar lines were long. All felt that improving the speed and efficiency of the line was needed.

Work flow. Teachers and garden coordinators stated that the salad bar program did not adversely affect their flow of work. Food-service staff reported a consistent need to work overtime in order to complete all duties for the salad bar, including an estimated 30 additional minutes for cleanup duties.

Leftovers. Food-service staff stated that they preferred to store leftovers at the school site for convenience, organization and the assurance of food safety, and because a delivery truck used to transport food to a storage space in the high school had no refrigeration unit. One staff member noted that it would be helpful to have proper storage procedures for leftovers. They also noted that there was not enough space to store salad bar items at the elementary schools.

Sustainability and partnerships. A major question raised by those interviewed was, "Can [the salad bar] pay for itself?" Some issues mentioned in relation to sustainability included: having adequate and consistent volunteers, managing labor costs and maintaining the quality of the salad bar without "cutting corners."

Garden coordinators and teachers agreed that their communication with parents was enhanced, particularly those involved in the school garden. However, one individual stated that more education about the salad bar 
needed to be provided to the parents. In contrast, partnership development among teachers, garden staff and foodservice staff was not as prominent. A major reason given was that teachers do not usually eat in the same area as the children; consequently, they do not interact with the food-service staff to create relationships.

These comments illustrate the complexity of introducing the program, the need for staff and student training on the use of the salad bar, and reasons why it is necessary to market the program to increase student participation.

\section{Nutrition and gardening education}

Teachers in the three pilot schools were surveyed to assess the current status of their nutrition and garden education, and attitudes and barriers associated with incorporating it into classroom curricula. The survey was administered to teachers in 2001-2002 and included close-ended questions about nutrition-related attitudes and knowledge, current practices, barriers to incorporating nutrition into the classroom, and using the garden to enhance academic instruction. Prior to administration, the questionnaire was pre-tested for clarity with 30 teachers not working at the three pilot schools. The final survey was composed of 17 questions and took 5 to 10 minutes to complete. Survey completion was voluntary and completely anonymous. Data from returned surveys were analyzed using SPSS 10.0.

Surveys were provided to all teachers $(n=118)$ at the three school sites; a total of 70 were returned, resulting in an overall response rate of $59 \%$, with $64 \%$ of respondents teaching at lower grade levels (K-3rd grade). Responses were similar among schools (except for subjects taught), so data for the three schools were combined.

Attitudes and knowledge. Nutritionrelated attitudes and knowledge were assessed using six scale questions, with answers ranging from 1 to 5 . When asked about the importance of providing nutrition education in the classroom, $84 \%$ rated it as "moderate" to "very" important, while $16 \%$ said it was "somewhat" important and none said it was not important at all.
As for the perceived feasibility of incorporating nutrition topics into the curriculum within the California Content Standards-based system, 63\% noted that it was "somewhat" to "moderately" feasible. A minority of teachers (13\%) perceived incorporation of nutrition topics as being "extremely" feasible, while $24 \%$ said it was "not" or of "low" feasibility. One teacher commented, "Time in the day is probably the single biggest hurdle. We're all trying to meet [state] standards, and need to figure out how to fit gardening lessons and activities into the existing curriculum."

When teachers were asked whether they were interested in having a nutrition expert teach nutrition in their classrooms, $82 \%$ responded as "somewhat" to "very" interested. Regarding perceived levels of nutrition knowledge, 97\% evaluated themselves as having a "moderate" to "high" level of nutrition knowledge.

Information sources. Of 14 sources of nutrition information offered in the survey, most teachers reported utilizing magazines (70\% to $90 \%)$, books $(70 \%$ to $98 \%$ ) and family (70\%). A slightly smaller percentage of teachers obtained information from college classes $(55 \%$ to $70 \%)$, friends (50\% to $65 \%$ ) and physicians $(60 \%$ to $70 \%)$. Only $20 \%$ to $30 \%$ of teachers reported obtaining information from a registered dietitian-nutritionist.

Classroom incorporation. Overall, nutrition was incorporated into the classrooms of $69 \%$ of teachers responding to the questionnaire. Due to the variability of nutrition topics taught among schools, this data is reported for individual schools (table 1). Eighty-six percent reported teaching nutrition and physical activity and 79\% taught about a healthy diet. Surprisingly, the USDA food guide pyramid was taught by only $41 \%$ of teachers. One topic that especially varied from school to school was label reading. It was taught by $100 \%$ of teachers at one school, but only by $25 \%$ to $30 \%$ of teachers at the two other schools.

Sixty-six percent reported that science was taught using nutrition, while nutrition was included in health instruction by $59 \%$ of teachers. A majority of teachers used the garden to teach subjects such as science $(90 \%)$, nutrition $(71 \%)$, language arts (64\%), environmental studies $(60 \%)$, health $(59 \%)$, agricultural studies $(57 \%)$ and math $(56 \%)$.

The group interviews provided additional details on teaching language arts with the garden. Teachers discussed positive student engagement in activities such as journal writing in the garden and frequent connections made with literature.

Barriers. The top three barriers to incorporating nutrition in the classroom were lack of time $(79 \%)$, lack of curriculum linked to standards $(61 \%)$ and lack of available resources (44\%). One teacher wrote: "There is not enough time to also teach nutrition. The state is too focused on core subjects and testing scores." As for the garden, $67 \%$ said that time was the largest barrier to using the garden to enhance academic instruction.

\section{Other program components}

Composting, waste reduction. The DJUSD piloted food-waste composting systems at the three
TABLE 1. Nutrition topics incorporated into elementary-school classrooms in Davis, Calif.

\begin{tabular}{|c|c|c|c|}
\hline \multirow[b]{2}{*}{ Topic } & \multicolumn{3}{|c|}{ School } \\
\hline & $\begin{array}{c}\text { Cesar Chavez } \\
(n=20)\end{array}$ & $\begin{array}{l}\text { Birch Lane } \\
(n=10)\end{array}$ & $\begin{array}{l}\text { Pioneer } \\
(n=40)\end{array}$ \\
\hline & \multicolumn{3}{|c|}{ 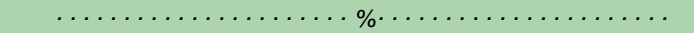 } \\
\hline Food guide pyramid & $45^{*}$ & 47.5 & 10 \\
\hline Healthy diet & 55 & 80 & 60 \\
\hline Label reading & 30 & 25 & 100 \\
\hline Diet and disease & 20 & 30 & 30 \\
\hline Nutrition and physical activity & 85 & 85 & 90 \\
\hline Serving sizes & 10 & 20 & 10 \\
\hline Diet and weight & 10 & 12.5 & 90 \\
\hline
\end{tabular}




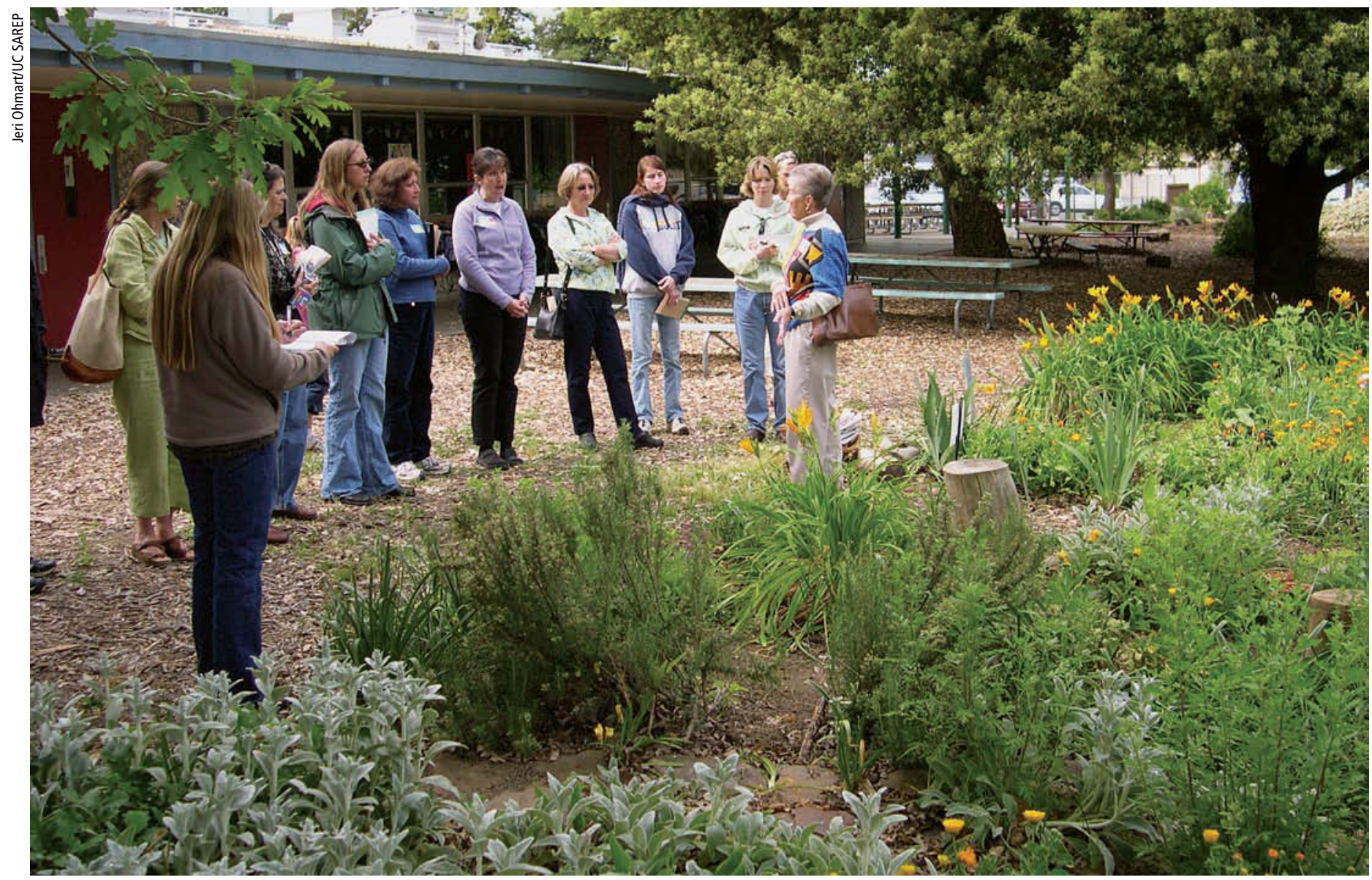

Dorothy Peterson, garden coordinator for the Davis school district, speaks to a group from the California Integrated Waste Management Board about the Farm to School Connection at Birch Lane Elementary School. Through the program's Food Waste Diversion Project, students learned to recycle lunch wastes and create compost for the garden; the gross savings from two schools was $\$ 6,230$ in disposal fees during one school year.

pilot schools during the 2000-2001 school year, under a contract with the CIWMB. The goal of the Food Waste Diversion Project was to develop and test site-specific systems to reduce the lunch waste stream and in particular to reduce the food components of lunch waste while engaging students in the ongoing practice of composting and recycling.

The program generated a gross savings of $\$ 6,230$ in disposal fees alone from waste reductions at Cesar Chavez and Pioneer schools. As of spring 2004 the composting program had been updated based on program plans and extensive fiscal data projections presented by the DJUSD garden coordinator, and it had become self-sustaining and expanded to all eight elementary schools within the district.

Farm tours. During spring 2002, 10 second-grade classes at two schools took daylong field trips to local farms, organized by CAFF's Farm to School coordinator. A classroom lecture tied to grade-level subject standards preceded the field trips, which provided handson learning and established connections between the garden, the salad bar, recycling, and the food and farming system. Teachers reported that the trips reinforced class time with real-life examples and experiences, and said that they would like to take their students on similar trips in the future.

CSA boxes. Another educational component of the Farm to School Connection was the provision of communitysupported agriculture (CSA) boxes obtained from local farmers. Boxes of farm fresh fruits and vegetables were donated to the three schools involved in the pilot program for use in classroom cooking sessions, science lessons or other educational purposes, such as nutrition education and art.

\section{Challenges and future directions}

Now in its fourth year, the Davis Farm to School Connection continues to evolve as it becomes more integrated into educational program delivery in schools within the district. School districts may use the information from this program to develop and enhance their own learning environments. Furthermore, this program serves as an example of how incorporating agricultural concepts within school curricula can facilitate teaching to the core curriculum standards for math, science, language arts and social science, an important aspect considering time constraints placed on teachers in California's current educational system.

The long-term mission of the DJUSD program is to integrate all parts of the seed-to-table cycle with activities and education, while furthering the district's educational goals for K-12. The instructional gardens and recycling components are fully integrated and self-sustaining at the elementary level. However, program development work is still necessary to achieve the mission, especially with Crunch Lunch and integration of education-related activities. 
Crunch Lunch is still undergoing adaptations to achieve self-sufficiency and sustainability. A primary concern is keeping the expenditures for farm fresh produce within an acceptable food-service budget; a major challenge in the coming years will be to reduce costs or increase income. School lunch participation increased with the addition of Crunch Lunch, but further increases in participation are necessary to attain sustainability. Part of increasing participation in the salad bars is learning how to effectively integrate the lunch program, school gardening, recycling and nutrition/ food education in the classroom.

Working with local farmers is a novel aspect of this program. It is essential that the individual who purchases produce for the salad bars is knowledgeable about farming, farmers' markets and building working relationships with farmers (Brillinger et al. 2003). Involvement of a forager in the past year to facilitate locating produce and communicate with the kitchen manager and farmers has been a positive addition to the program.

Agricultural, nutritional and environmental literacy for adults has surfaced as an important next step in creating a community climate that supports the concept of improving children's health. Data suggests that teachers perceive nutrition education as "somewhat" to "very" important; however, they also perceive it to be "somewhat" to only "moderately" feasible to incorporate into the classroom. In-service educational programs for teachers, including the use of curricula and activity guides that link farm-to-school components to the state's educational standards by subject and grade, were provided in spring 2004. Plans were also under way to engage community members in tangible ways by recruiting them as on-site volunteers.

Another consideration is developing and adopting related districtwide policies. District food policies can bring individuals together to support a common vision, facilitating focused efforts on a healthy nutritional environment (Briggs et al. 2003). The California Superintendent of Public Instruction, Jack O'Connell, issued a challenge to all school districts in 2003 to pass and implement comprehensive nutrition and physical activity policies.

A healthy school environment has the potential to provide students with the ability to make informed decisions about dietary choices, possibly altering their eating behaviors as adults. With 27 million school-aged children participating in the National School Lunch Program, access to quality food in school is a critical nationwide component of providing them with the tools to make informed dietary decisions (Briggs et al. 2003). The comprehensive program in Davis is an example of what is possible in the school environment and the impact that individuals with vision and dedication can have on the health of children.

H. Graham is Research Assistant, and S. Zidenberg-Cherr is Cooperative Extension Nutrition Science Specialist, Department of Nutrition, UC Davis; G. Feenstra is Food Systems Analyst, UC Sustainable Agriculture Research and Education Program; and A.M. Evans is Nutrition Education Consultant, California Department of Education, Nutrition Services Division, Sacramento. This research was supported by grants from the U.S. Department of Agriculture, Kellogg Foundation, California Integrated Waste Management Board and California Department of Education/Nutrition Services Division, SHAPE. We acknowledge all individuals involved in the program at the Davis Joint Unified School District, in particular David Murphy, Superintendent, and Raphaelita Curva, Director of Child Nutrition Services, as well as Renata Brillinger, Dorothy Peterson and Jeri Ohmart for their assistance.

\section{References}

Briggs M, Safaii S, Lane Beall D. 2003. Position of the American Dietetic Association, Society for Nutrition Education, and Ameri- can School Food Service Association Nutrition Services: An essential component of comprehensive school health programs. JADA 103:505-14.

Brillinger R, Ohmart J, Feenstra G. 2003. The Crunch Lunch Manual: A case study of the Davis Joint Unified School District and a fiscal analysis model. UC Sustainable Agriculture Research and Education Program. Davis, CA. www.sarep.ucdavis.edu (accessed 8/04).

[CDC] Centers for Disease Control and Prevention. 1996. Guidelines for school health programs to promote lifelong healthy eating. MMWR 45(RR-9):142.

CDC. 2003. Physical activity and good nutrition: Essential elements to prevent chronic diseases and obesity. www.cdc.gov/ nccdphp/dnpa (accessed 7/03).

[CDE] California Department of Education. 2002. Kids Cook Farm-Fresh Food: Seasonal Recipes, Activities and Farm Profiles that Teach Ecological Responsibility. Doc no 001547. Sacramento, CA. 248 p.

Epstein LH, Wing RR, Valoski A. 1985. Childhood obesity. Pediatr Clin North Am 32(2):363-79.

Feenstra G, Ohmart J. 2003. Yolo County farm to school project evaluation, third year annual report. UC Sustainable Agriculture Research and Education Program. p 1-28.

Foerster SB, Fierro MP, Gregson J, et al. 2002. California teens eating and exercise survey. Public Health Institute, Berkeley, CA. www.phi.org/library.html (accessed 8/04). p 1-36.

Graham H, Lane Beall D, Lussier M, et al. In press. Use of school gardens in California academic instruction. J Nutri Ed Behav.

Lieberman GA, Hoody LL. 1998. Closing the achievement gap: Using the environment as an integrating context for learning. Executive Summary: State Education and Environmental Roundtable. San Diego, CA. www.seer.org/pages/research.html (accessed 8/04).

Morris JL, Zidenberg-Cherr S. 2002. Garden-enhanced nutrition education curriculum improves fourth-grade school children's knowledge of nutrition and preferences for some vegetables. JADA 102(1):91-3.

Ogden CL, Flegal KM, Carroll MD, Johnson CL. 2002. Prevalence and trends in overweight among U.S. children and adolescents, 1999-2000. JAMA 288(14):1728-32. Rosenbaum AL, Joe JR, Winter WR. 1999. Emerging epidemic of type 2 diabetes in youth. Diabetes Care 22(2):345-54.

Schwimmer JB, Burwinkle TM, Varni JW. 2003. Health-related quality of life of severely obese children and adolescents. JAMA 289(14):1813-9.

Whitaker RC, Wright JA, Pepe MS, et al. 1997. Predicting obesity in young adulthood from childhood and parental obesity. N Engl J Med 337:869-73. 